\title{
Modes of Anti-angiogenesis in Chemical Perspectives
}

\author{
Shan Arif ${ }^{a, b}$, Muhammad Imran ${ }^{a, b}$, Muhammad Adnan Iqbal ${ }^{a, b}$
}

\begin{abstract}
Angiogenesis is a process which involves formation of new blood vessels and it involves the growth, migration and differentiation of endothelial cells that cause line inside the walls of blood vessels. This process is controlled by chemical signals in body and these signals such as vascular endothelial growth factor (VEGF), combine with receptors on the surface of normal endothelial cells and increase the growth and survival of new blood vessels. Some drugs are used to diminish the combining of VEGF with the receptors from sending the growth signals in new blood vessels. This process is called anti-angiogenesis and also called cancer growth blockers. In the current study, role of synthesized chemical pharmacores like Humulus lupulus, Hypericum perforatum, Panax ginseng, Coptis chinensis and Rheum palmatum as anti-angiogenesis has been compiled. The structure activity relationship in inhibiting the angiogenesis has also been discussed.
\end{abstract}

Keywords: Anti-angiogenesis, Genistein, Epigallocatechin Gallate/ EGCG, Angiostatin.

Abbreviations: VEGF - vascular endothelial growth factor

\subsection{Introduction}

Growing of new blood vessels from the pre-existing ones is called angiogenesis. This happens when there is a deviation in the oxygen or the nutrient supply to the veins. This may occur by physiological or pathological pathways (Carmeliet,

\section{Significance | This study can accelerate}

${ }^{*}$ Correspondence: Muhammad Adnan Iqbal, Assistant Professor, Department of Chemistry, University of Agriculture, Faisalabad-38040, Pakistan, E mail: adnan.iqbal@uaf.edu.pk

Edited by Md Shamsuddin S. Khan, Hawkesbury Institute for the Environment, University of Western Sydney, Hawkesbury Campus, Bourke Street, Richmond, NSW AUSTRALIA, and accepted by the Editorial Board October 7, 2018 (received for review September 2, 2018).
2005). Angiogenesis can be great or terrible. When it is good it is responsible for procedures like wound healing or direction of menstrual cycle. But when it is awful, it's outcome is tumor, kind or dangerous (Folkman 1971). Angiogenesis is controlled either by local or fundamentals chemical signals, coordinating with the endothelial cells (Mousa and Davis, 2017). Angiogenic support is extremely basic for the growth and metastasis at both local and systematic levels. Adopting the unusual angiogenesis is one of the significant worries of humanity in all. Cancer diagnosis, control and its treatment has been a great challenge for the scientists across the globe. Various ways are embraced to handle the cancer. Generally, it is being done by designing anti-angiogenesis agents innovatively, by identifying and turning off the action of endogenous factors involved in abnormal growth of blood vessels, by exploring the natural sources to hinder angiogenesis or by lessening the quick isolating endothelial cells spreading cancer. The angiogenic inhibitors are generally classified as follows;

a. Endothelial cell growth inhibitors: This class of inhibitors works basically by instigating apoptosis and consequently restarting the endothelial cell development. The best example is endostatin (Decker, 1998).

b. Angiogenesis-signaling blockers: These are the inhibitors, essentiall for fundamental fibroblast growth factors (bFGF) and VEGF. The best example is Avastin (Folkman, 2002).

c. The receptor blockers: They repress ECM eradication and synonymously to inhibitors of MMPs. These work by restarting the receptor activities of numerous development factors (Guba et al., 2002).

\subsection{Angiotherapy and its Mechanism}

Angiotherapy is similar to the abnormal vessels. It is getting a consideration from various strata of specialists due to its curosity, sustainability, non-invasiveness and out of the box approach. Before discussing the common angiotherapic system it will be smarter to feature a portion of its instruments.

The reason of angiotherapy is to hinder basic stages of

Author Affiliation:

a Department of Chemistry, University of Agriculture, Faisalabad-38040, Pakistan

${ }^{b}$ Organometallic and Coordination Chemistry Laboratory, University of Agriculture,

Faisalabad-38040, Pakistan

Please cite this article:

Arif, Shan; Imran, Muhammad; Iqbal, Muhammad Adnan. (2018). Modes of Anti-angiogenesis in Chemical Perspectives. Angiotherapy, 1(2), pages 078-086.

2207-8843/@ 2018 ANGIOTHERAPY, a publication of Eman Research Ltd, Australia. This is an open access article under the CC BY-NC-ND license. (http://creativecommons.org/licenses/by-nc-nd/4.0/).
(http://angiotherapy.emanresearch.org). 
angiogenesis. This can prompt lessened vessel porousness and blood perfusion, and vascular shrinkage which diminishes the likelihood of a tumor getting oxygen and nutrients (Condeelis and Pollard, 2006). Theoretically, anti-angiogenic therapy may return tumor blood vessels into the ordinary state, and enhance the quality and conveyance of cytotoxic therapeutic agents ( $D$ Souza, 2014). Hence, anti-angiogenic agents work by decreasing the permeability of blood vessels in tumors, and the scattering of interstitial liquids. This leads to a decrease in interstitial pressure and eventually reduces tumor hypoxia (Maeda et al., 2009). If anti-angiogenic therapy is utilized along with cytotoxic agents, the impact of these agents increase, while tumor vessels are at same time standardized (Damgé et al., 1990).

Angiogenesis can be regulated by stimulator substances like chemokines, development elements and extraordinary angiogenic enzymes, some endothelial receptors, and adhesion molecules; and also by some inhibitors like angiostatin and endostatin (Siddiqui et al., 2009). An imbalance between inhibitors and inducers levels can lead to host's of health related issues like cancer, arthritis, heart and brain ischemias (John et al., 2015). During angiogenesis a series of physiological events line each other in a very precise way. These include the scattering of the extracellular matrix; the migration, adhesion and expansion of endothelial cells; and tube formation (Maeda et al., 2009). For these reasons, the inhibitors of the pathological angiogenesis have promising potential in curing the angiogenesis diseases that establish the new class of therapeutic operators in the field of "angiotherapy". Studies have demonstrated that various nutraceutical agents, including those got from natural products, exhibit poor bioavailability when consumed orally (van Walsem et al., 2015). So far, large portion of new potential therapeutics have demonstrated poor pharmacokinetics and biopharmaceutical properties. Therefore, upgraded tranquilize conveyance frameworks are justifies to permit the circulation of therapeutically active drug molecules to the site of action, while limiting the exposure of solid organs and tissues to these molecules as much could reasonably be expected. By the application of Nanotechnology we may accomplish a proficient medication conveyance at the site of need with a maximum effectiveness and a minimum fuss. The safety profile of these drugs is likewise exceptional (El-Nahas et al., 2017). Phospholipids are believed to be valuable transporter molecules for drug delivery. They serve as vehicles for the drug molecules which should have been directed in controlled discharge forms (Xu et al., 2013). This method of planning will limit the toxicity and an improved solubility (Shin et al., 2007). Phytosome is a complex of the drugs that have amphillic properties. It has the ability to bind the phospholipids (Zhang et al., 2013). However, in this review article our focus is fundamentally on the various inhibitors, natural and manmade, with their chemical perspective in angiotherapy.

\subsection{Phytochemicals and Medicinal Herbs in Anti-Angiogenesis}

Different sorts of cancers are being treated by utilizing the traditional plant sources. The main reason is their almost no symptoms as compared to chemotherapy by synthetic compounds and economy of production (Cragg and Newman, 2005). A genuinely huge number of phytochemicals are found in plants. For example, phenolic diterpenes, flavonoids, polyphenolic acids and tannins (Dawidowicz et al., 2006). Plant Polyphenolics, especially, have drawn the attention because of their potential use as therapeutic agents to target cancer, heart diseases and angiogenesis (Yoysungnoen et al., 2008). Polyphenolics are typically wealthy in antioxidants (Münzel et al., 2010), and contribute in anti-proliferation, anti-carcinogenic and anti-neovascularization processes. Even few phenolics and flavonoids are accounted to diminish the production of reactive oxygen species (ROS) in biological frameworks. ROS create oxidative pressure and contribute in pathologies related with cancer and extreme vascularization. The cancer that develops due to ROS is malignant due to mutations in gene expression and DNA (Kampa et al., 2007). A few in vivo and in vitro reports have demonstrated the ability of flavonoids to hinder the cancer growth (Batra and Sharma, 2013). In initial stages of cancer flavonoids hinder metabolic activation of carcinogens. In later phases, they induce apoptosis, inhibit cancer cell proliferation and tumor metastasis (Clere et al., 2011).

The presence of phenolic compounds in redox frameworks acts in a multifaceted manner. They may either act as hydrogen donators, diminishing agents, a metal chelating agents or in some cases as singlet oxygen quenchers (Gordon, 1990). Phenolic compounds also help to kill the free radicals generated in the metabolic pathways (Gordon, 1990). Conclusion from these investigations obviously demonstrates a connections between flavonoids, phenolics and their anti-angiogenic, anti-proliferatory and anti-oxidant activities (Stoclet et al., 2004). Diagrammatic classification of polyphenols (flavonoids) has been shown in Figure 3.1.

\subsection{Epigallocatechin Gallate/ EGCG}

Epigallocatechin gallate (EGCG) is a type of catechin. Its distinctive fixations are found in different varieties of tea. The fruits like apple, plums etc. have trace amount of EGCG in them (Bhagwat et al., 2014; Rashidi et al., 2017). Its structure has been shown in Figure 3.2. Anticancer activity of EGCG is related with the inhibition of invasion by hindering the movement of urokinase (Fujiki et al., 2018; Suganuma et al., 2016) or the matrix metalloproteinases (MMPs) (Garbisa et al., 2001), or by the expulsion of oxygen radicals (Zhang et al., 2000), all of which play key roles in cancer invasion and metastasis. Analysis proposed that green tea consumption by mice has significantly hinder angiogenesis. Few measures of corneal neovascularization like 


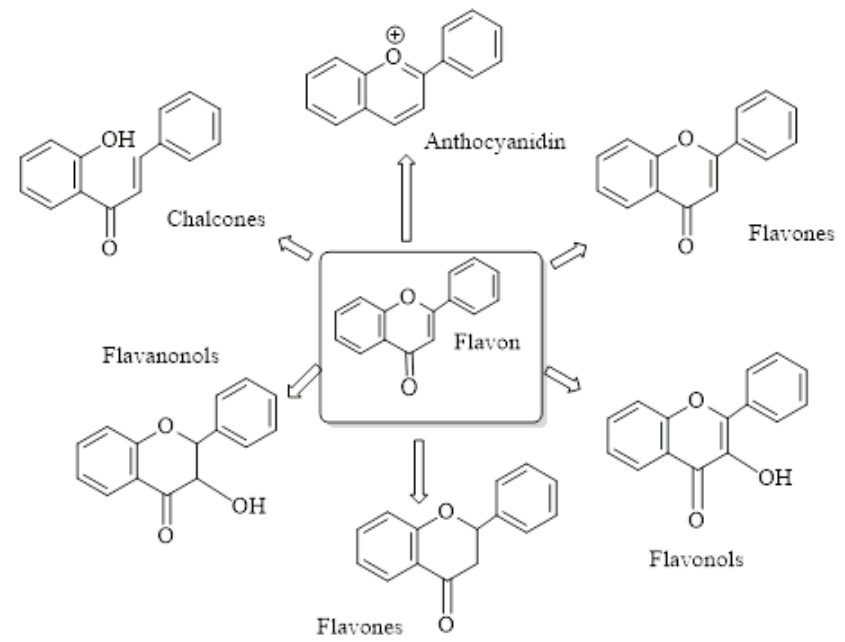

Figure 3.1 | Different groups of flavonoids.<smiles>O=C(OC1Cc2c(O)cc(O)cc2OC1c1ccc(O)c(O)c1)c1cc(O)c(O)c(O)c1</smiles>

EGCG

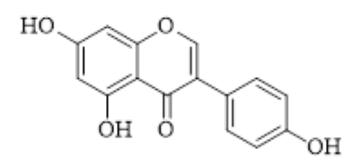

(a)

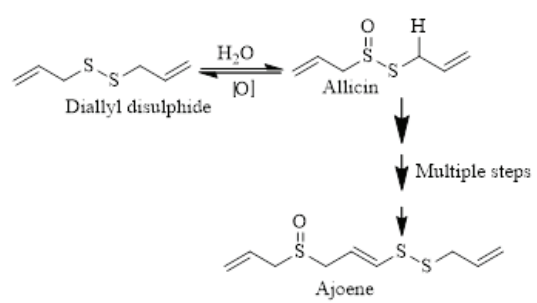

(b)
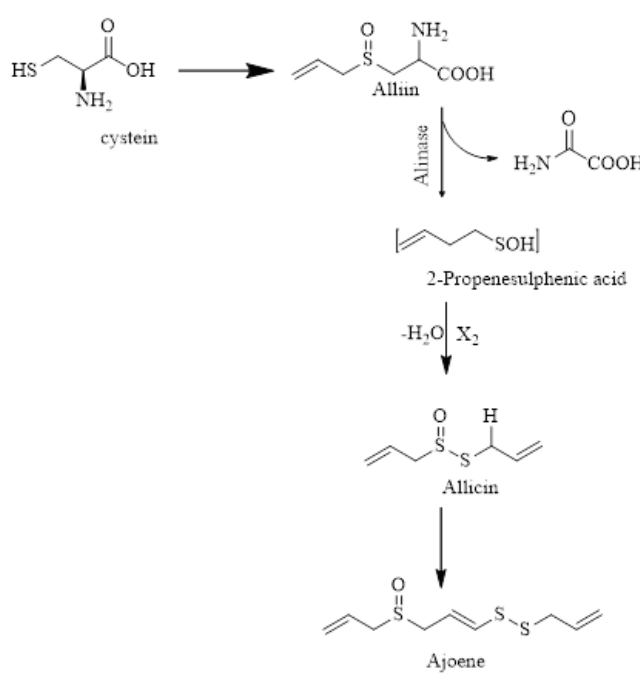

Figure 3.3 | (a) Diallyl disulphide pathway for Ajoene formation and (b) Cystein pathway for Ajoene formation.

HUVEC's proliferation (Mojzis et al., 2008). Its structure is shown in figure 3.2 .

\subsection{Garlic (Allium sativum) and Anti-angiogenesis}

Sulfur-rich Allium are regularly good dietary source of selenium (Se), which is frequently inadequate in the human diet and is essential for antioxidative, protective enzymes (González-Morales et al., 2017), Anticancer role of allicin found in garlic was first discovered by Cavallito in 1944 (Block, 2010). Allicin in garlic disintegrtes into ajoene and diallyl disulfide in a series of steps, as shown below. All these compounds were found to have exceptional anti-cancer activities (Sela et al., 2008). Some of these pathways are illustrated in figure 3.3 (a) and (b) (Block et al., 2017). Florinated compounds of allicin and ajoene were synthesized by a number of ways in figure 3.4 (a) and (b).

Besides these chemicals, there are certain plant sources like Humulus lupulus, Hypericum perforatum, Panax ginseng, Coptis chinensis and Rheum palmatum are evident to have anti-cancer properties (Varinska et al., 2010). How there is still so much debatable, their actual role anti-cancer chemicals cannot be acknowledged except if approved by authenctic scienticfic principles (Dulak, 2005).

\section{Naturally found Inhibitors of Angiogenesis}

A number of naturally occurring inhibitors have been explored and investigated, among the most widely recognized are angiostatin, interferons, endostatin, a few interleukins and retinoic acid.

Angiostatin 
Angiostatin is produced by the cleavage of amino terminal fragment of plasminogen and acts as an endogenous inhibitors of angiogenesis. It is composed of three to five kringle domains (See Sturcture 3.5). Its major effects incorporate the hindrance of EC migration or their proliferation. An X-ray crystallographic picture of angiostatin shows that one of its kringle structures, K1-3, has exceptional proclivity with proteins and makes it a valuable inhibitor (Abad et al., 2002).

\section{Retinoic acid (RA)}

Retinoic acid (RA) is the parent compound and four types of generations of retinoids got from it. Retinoids impact an expansive range of procedures connected with vessel formation, separation and so on. (Altucci and Gronemeyer, 2001). RA is yet another potential inhibitor of angiogenesis. RA showed very amazingly potential when employed on rats with thyroid cancer. It reduced the cell expansion and the secretion of VEGF. Similarly, the volumes of tumours were also reduced in the animals, receiving treatment with RA (Hoffmann et al., 2007). First and second era retinoids include retinol and etretinate individually and demonstrate a marked ability to bind with the receptors shown in figure 3.6.

Studies suggest that retinoids are valuable in the treatment of cancers related to thyroid, prostate or colon. A similar study carried out by Spitzwig in 2003 has demontrated the adequacy of RA by the stimulation of sodium iodide symporter of thyroid carcinoma. (Spitzweg et al., 2003). Unfortunately, currently it is elusive any plant based compounds used in angiotherapy.

\subsection{Common Synthetic Angiogenic Inhibitors \\ 4.1 Thalidomide}

It is use for the treatment of disease and cancers (Uhl et al., 2006). A novel use of Thalidomide to restrain angiogenic vascularization in rodents (D'Amato et al., 1994). Birth defects caused because of Thalidomide were investigated (Vargesson, 2009). Thalidomide has many side-effects due to metabolic activity and one of these products is CPS49, a fluorinated analogues of thalidomide (synthesis shown in figure 4.1). CPS49 when applied to the upper half of a developing chicken embryo, the blood vessels started to break down very rapidly (Therapontos et al., 2009).

Thalidomide and its analogues influence different tissues and process like angiogenesis by interfering their cytoskeleton. The ability of thalidomide to bind specific endothelial cells is still enigmatic (Kusumbe et al., 2014). Although thalidomide has experienced an abnormal shift in status from the epitome of favouritism to the abyss of rejection and recapturing the lost magnificence. Its conceivable use in the angiotherapy can be visualized in near future because of some hopeful findings.

\section{Lenalidomide}

Another analogue of thalidomide, lenalidomide (shown in figure $4.2(\mathrm{a})$ ) has demonstrated its immunomodulatory potential for nemerous myeloma. Oral administration of lenalidomide impedes the growth factor linked angiogenesis and endothelial cell migration. The conceivable acivity of this medication is may be through akt phosphorylation pathway. Bevcizumab or Avastin (shown in figure 4.2 (b)) has an instigated impact on VEGF induced proliferation on human umbilical vein endothelial cells and neovascularization of corneal cells. The reaction was independent of concentrations of a vastin used (Han et al., 2009).

\section{Sunitinib}

Sunitinib is a tyrosine kinase inhibitor utilized in renal carcinoma and gastrointestinal tumours. Mendelsohn and Karas revealed that oral organizaion of sunitinib to athymic bare mice inhibited the growth of many human tumor xenografts. It was reported that a single oral dose $(40 \mathrm{mg} / \mathrm{kg}$ ) inhibited (i) VEGFR2 phosphorylation in mice in vivo bearing the A375 melanoma or (ii) PDGFRb phosphorylation in mice bearing the SF767T glioma. This schedule successfully blocked receptor phosphorylation for more than 12 but less than $24 \mathrm{~h}$. Despite the absence of continuous restrain of receptor phosphorylation, this regimen effectively decreased mean vascular thickness (a measure of anti-angiogenesis) and controlled tumor growth. The authors concluded that maintaining plasma sunitinib forces above $125 \mathrm{nM}$ $(50 \mathrm{ng} / \mathrm{mL}$ ) for $12 \mathrm{~h}$ on a once daily oral spoke to an initial therapeutic goal in human clinical trials (Mendelsohn and Karas, 1999). Structure is shown in figure 4.3.

\section{Possible Hazards of Anti-angiogenesis Inhibitors}

Therapeutic treatment utilizing these inhibitors may cause postponed wound healing and even hypertension. Tissues may create resistance either innately or by acquisition. Furthermore, a shortage of valid and predictive biomarkers has still numerous inquiries to be addressed acceptably (Chen and Cleck, 2009).

\section{Angiotherapy Using Protein Inhibitors Metalloproteinases}

They are also called matrixins and are endopeptidases containing zinc (Verma and Hansch, 2007). These compounds degrade extracellular matrix proteins. It is believed that that they also shape the cell conduct like cell expansion, migration, separation, apoptosis and angiogenesis (Van Lint and Libert, 2007). The zinc binding part of the enzyme is basic for its activity, the part named as $P_{1}$ is real determinant of its activity, the part named as a provides the enzyme its major pharmacokinetic properties, the sites showing points $\mathrm{P}_{2}$ and $\mathrm{P}_{3}$ are accessible for extensive variety of substituents, all these groups are upheld on a succinate type of backbone (structure shown n figure 4.4). Formation of new vessels is an exceptional and complex process. A typical antigenic process involves the stimulation of walls of endothelial cells of an officially existing capillary. After this human metalloproteinases (hMPs) make space for the attack of new cells by dissolving and breaking the extracellular framework in proteinaceous shape. This follows the mitotic procedure generating new endothelial cells. These cells are 
(a)<smiles>C/C=C(/F)Cl</smiles>

1-chloro-1-fluoropropene

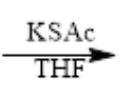

FlorinatedThioacetate<smiles>C=C(F)CSSCC(=C)F</smiles>

Florinated disulphide $\mathrm{CH}_{3} \mathrm{COOH}$
$42 \%$<smiles>C=C(F)CS(=O)CC(=C)F</smiles>

Difloroallicin

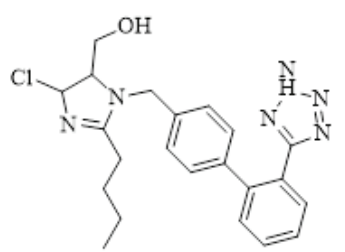

Figure 3.5 | Structure of Angiostatin.
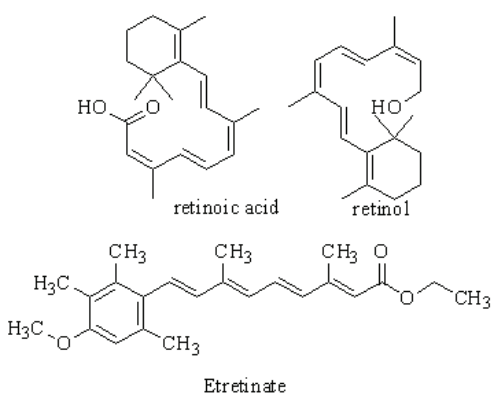

Figure 3.6 | Shows the ability of retinoids to binds with receptor. 1-chloro-1-fluoropropene FlorinatedThioacetate<smiles>C=C(F)CSSCC(=C)F</smiles>

Florinated disulphide $\mathrm{CH}_{3} \mathrm{COOH}$
$42 \%$<smiles>C=C(F)CS(=O)CC(=C)F</smiles>

Difloroallicin $\left(\mathrm{CF}_{3}\right) 2 \mathrm{CHOH}$ $59 \%$

$\uparrow$<smiles>C=C(F)CSSC=C(F)CS(=O)CC(=C)F</smiles>

Trifloroajoene

Figure 3.4 | (a) Synthesis of florinated allicin and (b) Synthesis of trifloroajoene.

the result of this rearranged process responsible for vessel formation. In this way a system of vessels is established which helps and supports in cancer growth (Pavlakovic et al., 2001).

\section{Angiogenin}

Another potential inhibitor of dangerous angniogenesis is Ribonuclease 5 or Angiogenin. Recent investigations has demonstrated a reasonable relationship between Angiogenin and tumour growth ( $\mathrm{Li}$ and $\mathrm{Hu}, 2012$ ). When it is translocated to the cell nucleus, the result is the upregualtion of the rRNA associated with the procedure of transcription whereas the thump down strains way to the downregulation of rRNA (Gao and Xu, 2008). Angiogenin is thought to influence the human cell line or Hela by interfering in its ability to multiply and this manner is considered to be a potential therapeutic remedial in future (Tsuji et al., 2005). The figure 4.5 is showing the upregualtion of a DNA strand into RNA within the sight of ribonuclesase.

\section{Estrogens}

There are three major types of estrogens as estrone (figure 4.6 (a)), estradiol (b), and estriol (c). Estrogens work by managing the cell events by activating their specific family. These receptors are called estrogen receptors (ERs). These ERs regulate a host genes engaged in the vascularization. This is apparent from the presence of enzyme aromatase in the recently growing blood vessels and Endothelial cells (ECs) (Mendelsohn and Karas, 1999). In a study including the mice insufficient in ERs were produced and then their angiogenic functionality was monitored, it was 


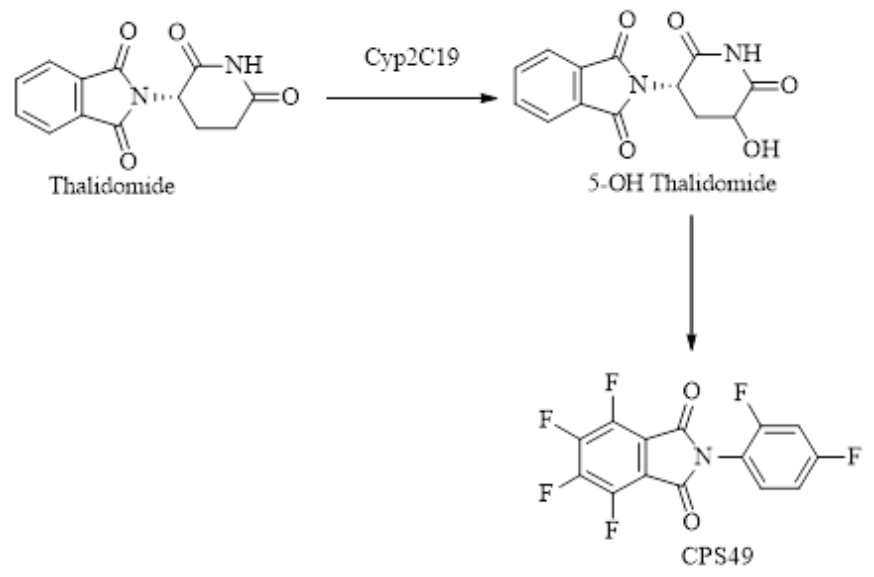

Figure 4.1 | Breakdown of thalidomide

(a)<smiles>Nc1cccc2c1CN(C1CCC(=O)NC1=O)C2=O</smiles>

(b)

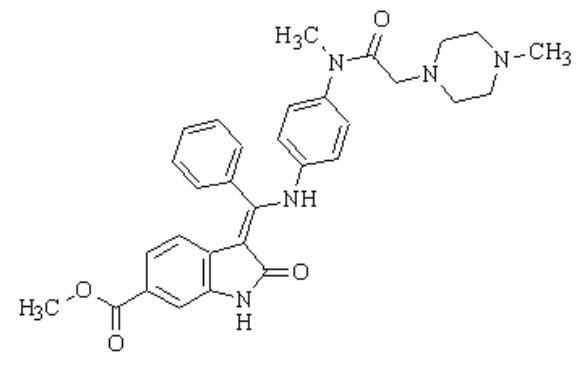

Figure 4.2 | (a) Chemical structure of Lenalidomide and (b) Chemical structure of Bevacizumab/Avastin.

observed that these mice had host genes and many types of vasculature abnormalities (Zhu et al., 2002). This demonstrates the importance of estrogens in expression of many genes that participate in the new blood vessel formation processes (Tamura et al., 2002).

\section{Interleukins}

Interleukins are a wide variety of proteins that are associated with the motioning inside and over the cells. These are produced by leukocytes (Sims et al., 1988). Out of a few human interleukins being studied are being considered for various jobs, Interleukin 8 (IL-8) is the most critical one with context to inflammatory and angiogenic functions. It is discharged by the antigens and releases the signals essentials for vasculature formation. The chemotectic activity of interleukin 8 causes the vasoconstriction at the site of aggravation and back off the blood flow at the purpose of contamination. IL-8 is thought to give rise to colorectal disease by acting as an autocrine and perhaps separating the metalloprotein molecules (Itoh et al., 2005).

\section{Basic Fibroblast Growth Factor (bFGF)}

Basement membranes (BM) contain basic Fibroblast Growth Factor (bFGF) which is hypothesized to encourage the process of<smiles>CCN(CC)CCNC(=O)c1c(C)[nH]c(/C=C2\C(=O)Nc3ccc(F)cc32)c1C</smiles>

Figure 4.3 | Chemical structure of Sunitinib.

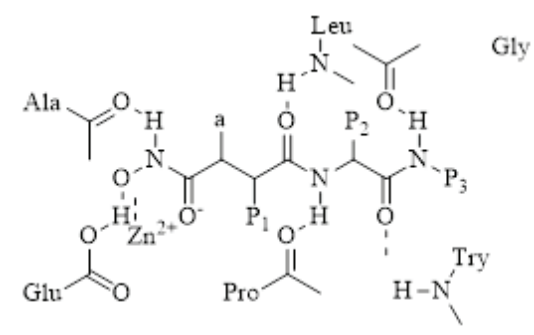

Figure 4.4 | Structure of a human metalloproteinase wound healing and fresh blood vessel formation or angiogenesis (Pavlakovic et al., 2001). An examination was done to talk about the role of bFGF on endothelial progenitor cells (EPCs). It was observed that bFGF has increased the angiongenesis. Application of bFGF as a therapeutic target for cartilage associated to cancer or chondrosarcoma (Therapontos et al., 2009).

\section{Vascular Endothelial Growth Factor (VEGF)}

Vascular Endothelial Growth Factor (VEGF) is among the most important contributors of angiogenesis and tumorigenesis (Bergers and Benjamin, 2003). It can actuate or all over again angiogenesis. The type of cells in which it indicates activity range from muscle cells to neurons, however, its key role is on the endothelial cells (shown in figure 4.7). The functions performed by Vascular Endothelial Growth Factor (VEGF) incorporate the expression of genes, permeability of vessels, cell expansion, migration and their survival (Adair and Montani 2010). All this is done when VEGF bind to their receptors, although the pathway in each case might be unique. Studies on laboratory rats uncover that the VEGF concentration was higher in the embryonic stages and any variation from the norm in them resulted in adverse results ( $\mathrm{Ji}$ et al., 2013). A portion of the pathways received by VEGF in their 

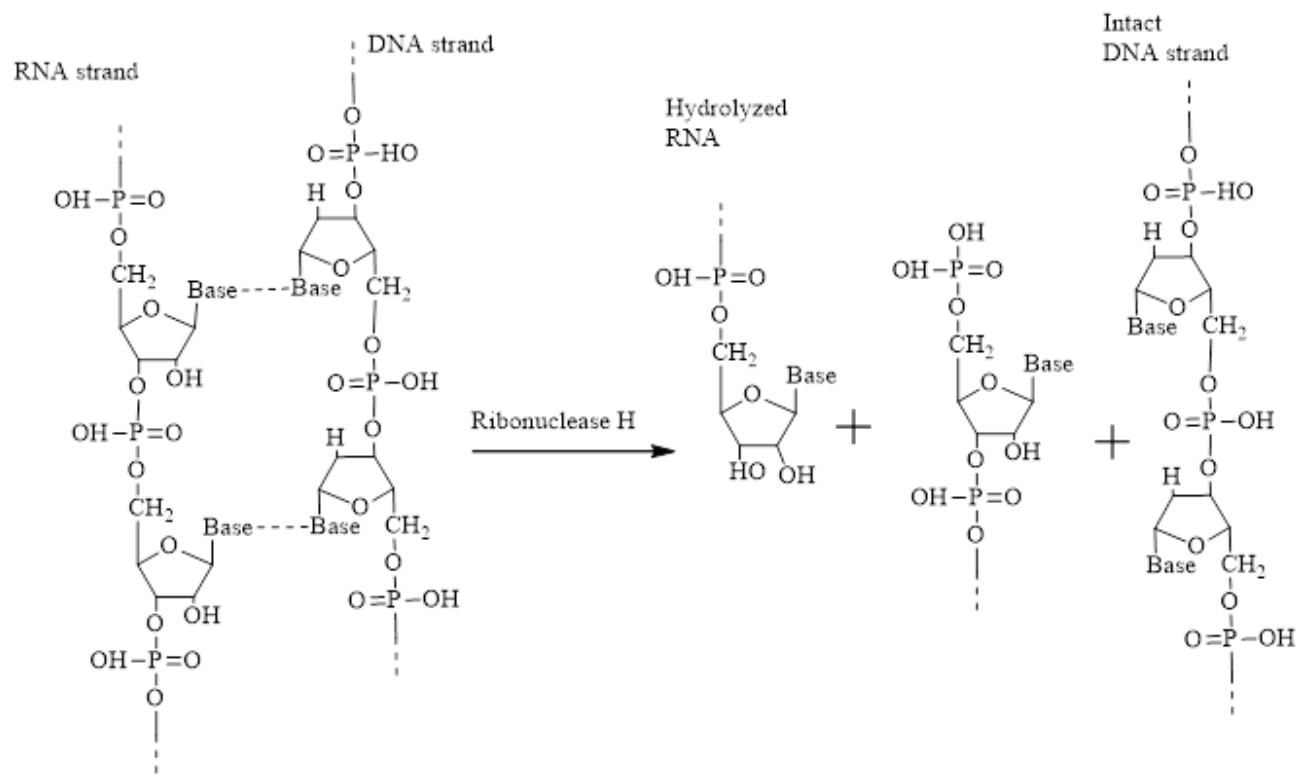

Figure 4.5 | Working of Ribonuclease on Strands of DNA

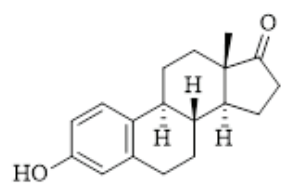

(a)

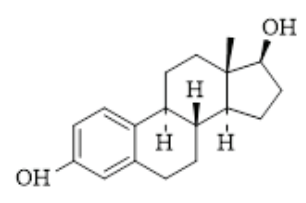

(b)

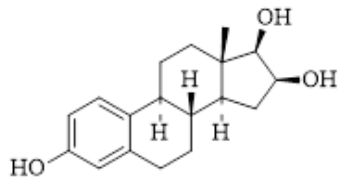

(c)

Figure 4.6 | (a). Structure of estrone, (b) Structure of estradiol and (c) Structure of estriol

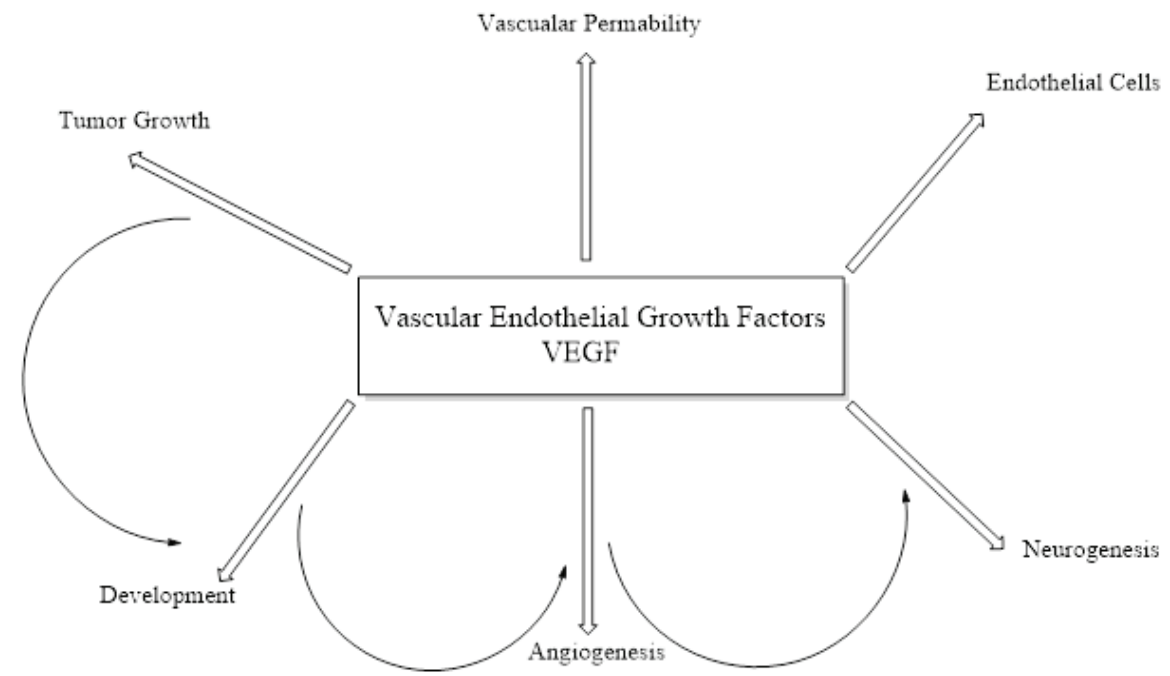

Figure 4.7 | Shows factors for VEGF

activity are illustrated in figure 4.7 (Suárez and Sessa, 2009).

Angiotherapy has far more encouraging impacts when contrasted with the chemotherapy. The purpose of chemotherapy is to kill he cancer cells directly or indirectly. Therefore, there are worthy chances of unexpected side effects and changes. As a result, the possibility to control the cancers will pose much tougher challenges in future.

On the other hand inhibitor instigated angiotherapy is more encouraging and safe. The purpose here is not to kill the cancerous cell however to focus on endothelial cell. This significantly diminishes the hazard reactions. At the point when the blood supply to the cancerous cells is disturbed or made restricted, the movement of cancer will be limited and slowed down.

Similarly, chemotherapeutic techniques maybe constantly pass on to death sentence to the cancerous cells but the inhibitors, I can say, give another 'expectation' to cells by doing so much to stop the tumor. For example to make the surrounding conditions more benevolent and favourable.

Some limitations 
Since the movement of cancers follows very exceptional processes, therefore their comprehension is not a simple assignment. Each abnormal growth of vessels forces another challenge for the researchers on one hand and furthermore opens new horizons to be explored again. Despite everything we need authentic and valid biomarkers to highlight their clear route. Similarly, the knowledge of different signaling insruments (Suárez and Sessa, 2009) is still poorly understood and is basically based on suppositions rather than established facts. The logic behind the absence of spotlight on the auxiliary properties of different synthetics utilized. The most neglected area is perhaps the lack of focus on the structural properties of the different chemicals created. If a repository of various properties of different classes of chemicals and the groups is developed, this will truly encourage our motivation. A perfects model is the work on analogues of organosulphur compounds from garlic.

\section{Future Possibilities}

Anti-angiogenic treatment is getting increasingly advanced with the appearance of innovation. The spread of tumors presently being understood with current instruments like getting a magnetic resonance image of the affected site, HPLC, FT-IR, SEM, TEM, and likewise physico-chemical spectral analyses can also be utilized to upgrade and make the research yield more gainful, genuine and legitimite.

\section{Suggestions}

A varied methodology can be more productive in angiotherapy. The findings with encouraging results should be put to more through experimentation. This will help to limit the region of interest and make our work more focused.

\section{Author contributions}

Mr. Imran initially started the manuscript. It was further polished by Mr. Shan. The corresponding author managed these students to compile the manuscript in its final form.

\section{Acknowledgement}

The authors are grateful to

\section{Competing financial interests}

Authors have declared that no competing interest exists.

\section{References}

Abad, M. C., Arni, R. K., Grella, D. K., Castellino, F. J., Tulinsky, A. \& Geiger, J. H. (2002). The X-ray crystallographic structure of the angiogenesis inhibitor angiostatin. Journal of molecular biology 318(4): 1009-1017.

Adair, T. H. \& Montani, J. P. Angiogenesis. San Rafael (CA): Morgan \& Claypool Life Sciences; 2010. Chapter 1, Overview of Angiogenesis.

Altucci, L. \& Gronemeyer, H. (2001). The promise of retinoids to fight against cancer. Nature Reviews Cancer 1(3): 181-193.

Batra, P. \& Sharma, A. K. (2013). Anti-cancer potential of flavonoids: recent trends and future perspectives. 3 Biotech 3(6): 439-459

Bergers, G. \& Benjamin, L. E. (2003). Angiogenesis: tumorigenesis and the angiogenic switch. Nature Reviews Cancer 3(6): 401-410.

Bhagwat, S., Haytowitz, D. B. \& Holden, J. M. (2014). USDA database for the flavonoid content of selected foods, Release 3.1. US Department of Agriculture: Beltsville, MD, USA

Block, E. (2010). Garlic and other alliums: The lore and the science. Royal society of
Chemistry.

Block, E., Bechand, B., Gundala, S., Vattekkatte, A., Wang, K., Mousa, S. S., Godugu, K., Yalcin, M. \& Mousa, S. A., (2017). Fluorinated analogs of organosulfur compounds from garlic (Allium sativum): Synthesis, chemistry and anti-angiogenesis and antithrombotic Studies. Molecules 22(12): 2081

Cao, Y. \& Cao, R. (1999). Angiogenesis inhibited by drinking tea. Nature 398: 381.

Carmeliet, P. (2005). Angiogenesis in life, disease and medicine. Nature 438: 936.

Chen, H. X. \& Cleck, J. N. (2009). Adverse effects of anticancer agents that target the VEGF pathway. Nature reviews Clinical oncology 6(8): 465-477.

Clere, N., Faure, S., Martinez, M. C. \& Andriantsitohaina, R. (2011). Anticancer properties of flavonoids: roles in various stages of carcinogenesis. cardiovascular \& hematological agents in Medicinal Chemistry 9(2): 62-77.

Condeelis, J. \& Pollard, J. W. (2006). Macrophages: Obligate partners for tumor cell migration, invasion, and metastasis. Cell 124(2): 263-266.

Cragg, G. M. \& Newman, D. J. (2005). Plants as a source of anti-cancer agents. Journal of Ethnopharmacology 100(1): 72-79.

D' Souza, S. (2014). A Review of In Vitro Drug Release Test Methods for Nano-Sized Dosage Forms. Advances in Pharmaceutics 2014: 12.

D'Amato, R. J., Loughnan, M. S., Flynn, E. \& Folkman, J. (1994). Thalidomide is an inhibitor of angiogenesis. Proceedings of the National Academy of Sciences USA 91(9): 4082-4085.

Damgé, C., Michel, C. Aprahamian, M., Couvreur, P \& Devissaguet, J. P. (1990). Nanocapsules as carriers for oral peptide delivery. Journal of Controlled Release 13(2): 233-239.

Dawidowicz, A. L., Wianowska, D. \& Baraniak, B. (2006). The antioxidant properties of alcoholic extracts from Sambucus nigra L. (antioxidant properties of extracts). LWT - Food Science and Technology 39(3): 308-315.

Decker, E. A. (1998). Strategies for manipulating the prooxidative/antioxidative balance of foods to maximize oxidative stability. Trends in Food Science \& Technology $9(6): 241-248$.

Dulak, J. (2005). Nutraceuticals as anti-angiogenic agents: hopes and reality. Journal of Physiology and Pharmacology. Supplement 56(1): 51-69.

El-Nahas, A. E., Allam, A. N., Abdelmonsif, D. A. \& El-Kamel, A. H. (2017). Silymarin-Loaded Eudragit Nanoparticles: Formulation, Characterization, and Hepatoprotective and Toxicity Evaluation. AAPS PharmSciTech 18(8): 3076-3086.

Farina, H. G., Pomies, M., Alonso, D. F. \& Gomez, D. E. (2006). Antitumor and antiangiogenic activity of soy isoflavone genistein in mouse models of melanoma and breast cancer. Oncology reports 16(4): 885-891.

Folkman , J. (1971). Tumor Angiogenesis: Therapeutic Implications. New England Journal of Medicine 285(21): 1182-1186

Folkman, J. (2002). Role of angiogenesis in tumor growth and metastasis. Seminars in Oncology 29(6): 15-18.

Fujiki, H., Watanabe, T., Sueoka, E., Rawangkan, A. \& Suganuma, M. (2018). Cancer prevention with green tea and its principal constituent, EGCG: from early investigations to current focus on human cancer stem cells. Molecules and Cells 41(2): 73-82

Gao, X. \& Xu, Z. (2008). Mechanisms of action of angiogenin. Acta biochimica et biophysica Sinica 40(7): 619-624.

Garbisa, S., Sartor, L., Biggin, S., Salvato, B., Benelli, R. \& Albini, A. (2001). Tumor gelatinases and invasion inhibited by the green tea flavanol epigallocatechin-3-gallate. Cancer 91(4): 822-832.

González-Morales, S., Pérez-Labrada, F., García-Enciso, E. L., Leija-Martínez, P., Medrano-Macías, J., Dávila-Rangel, I. E., Juárez-Maldonado, A., Rivas-Martínez, E. N., \& Benavides-Mendoza, A. (2017). Selenium and sulfur to Produce Allium Functional Crops. Molecules 22(4): 558

Gordon, M. H. (1990). The Mechanism of antioxidant action in vitro. Food Antioxidants, 1-18 (Ed B. J. F. Hudson). Dordrecht: Springer Netherlands.

Granese, R., Bitto, A., Polito, F., Triolo, O., Giordano, D., Santamaria, A., Squadrito, F.,\& D'Anna, R. (2015). Genistein reduces angiogenesis and apoptosis in women with endometrial hyperplasia. Botanics Targets and Therapy 2015(1): 27-32.

Guba, M., von Breitenbuch, P., Steinbauer, M., Koehl, G., Flegel, S., Hornung, M., Bruns, C. J., Zuelke, C., Farkas, S., Anthuber, M., Jauch, K.-W. \& Geissler, E. K. (2002). Rapamycin inhibits primary and metastatic tumor growth by antiangiogenesis: involvement of vascular endothelial growth factor. Nature Medicine 8: 128 .

Han, Y. S., Lee, J. E., Jung, J. W. \& Lee, J. S. (2009). Inhibitory effects of bevacizumab on angiogenesis and corneal neovascularization. Graefe's Archive for Clinical and Experimental Ophthalmology 247(4): 541-548.

Hoffmann, S., Rockenstein, A., Ramaswamy, A., Celik, I., Wunderlich, A., Lingelbach, S., Hofbauer, L. C. \& Zielke, A. (2007). Retinoic acid inhibits angiogenesis and tumor growth of thyroid cancer cells. Molecular and cellular endocrinology 264(1-2): 74-81

Itoh, Y., Joh, T., Tanida, S., Sasaki, M., Kataoka, H., Itoh, K., Oshima, T., Ogasawara, N. Togawa, S. \& Wada, T. (2005). IL-8 promotes cell proliferation and migration through metalloproteinase-cleavage proHB-EGF in human colon carcinoma cells. Cytokine 29(6): 275-282

Ji, Y., Lu, X., Zhong, Q., Liu, P., An, Y., Zhang, Y., Zhang, S., Jia, R., Tesfamariam, I. G. \& Kahsay, A. G. (2013). Transcriptional profiling of mouse uterus at pre-implantation stage under VEGF repression. PloS one 8(2): e57287.

John, J. V., Park, H., Lee, H. R., Suh, H. \& Kim, I. (2015). Simultaneous extraction of phosphatidylcholine and phosphatidylethanolamine from soybean lecithin. European Journal of Lipid Science and Technology 117(10): 1647-1654.

Kampa, M., Nifli, A.-P., Notas, G. \& Castanas, E. (2007). Polyphenols and cancer cell growth. Reviews of Physiology, Biochemistry and Pharmacology, 79-113 (Eds S. G. Amara, E Bamberg B. Fleischmann, T. Gudermann, S. C. Hebert, R. Jahn, W. J. Lederer, R. Lill, A. Miyajima, S. Offermanns and R. Zechner). Berlin, Heidelberg: Springer Berlin Heidelberg.

Kusumbe, A. P., Ramasamy, S. K. \& Adams, R. H. (2014). Coupling of angiogenesis and osteogenesis by a specific vessel subtype in bone. Nature 507(7492): 323.

Li, S. \& Hu, G. F. (2012). Emerging role of angiogenin in stress response and cell survival under adverse conditions. Journal of cellular physiology 227(7): 2822-2826. 
Maeda, H., Bharate, G. Y. \& Daruwalla, J. (2009). Polymeric drugs for efficient tumor-targeted drug delivery based on EPR-effect. European Journal of Pharmaceutics and Biopharmaceutics 71(3): 409-419.

Mendelsohn, M. E. \& Karas, R. H. (1999). The protective effects of estrogen on the cardiovascular system. New England journal of medicine 340(23): 1801-1811.

Mojzis, J., Varinska, L., Mojzisova, G., Kostova, I. \& Mirossay, L. (2008). Antiangiogenic effects of flavonoids and chalcones. Pharmacological Research 57(4): 259-265.

Mousa, S. A. \& Davis, P. J. (2017). Angiogenesis and anti-angiogenesis strategies in cancer. In Anti-Angiogenesis Strategies in Cancer Therapeutics, 1-19: Elsevier.

Münzel, T., Gori, T., Bruno, R. M. \& Taddei, S. (2010). Is oxidative stress a therapeutic target in cardiovascular disease? European Heart Journal 31(22): 2741-2748.

Pavlakovic, H., Havers, W. \& Schweigerer, L. (2001). Multiple angiogenesis stimulators in a single malignancy: implications for anti-angiogenic tumour therapy. Angiogenesis 4(4): 259-262

Pratheeshkumar, P., Son, Y.-O., Budhraja, A., Wang, X., Ding, S., Wang, L., Hitron, A., Lee, J.-C., Kim, D., Divya, S. P., Chen, G., Zhang, Z., Luo, J. \& Shi, X. (2013). Luteolin inhibits human prostate tumor growth by suppressing vascular endothelial growthfactor receptor 2-mediated angiogenesis. PLoS One 7(12): e52279

Rashidi, B., Malekzadeh, M., Goodarzi, M., Masoudifar, A. \& Mirzaei, H. (2017). Green tea and its anti-angiogenesis effects. Biomedicine \& Pharmacotherapy 89 949-956.

Sela, U., Brill, A., Kalchenko, V., Dashevsky, O. \& Hershkoviz, R. (2008). Allicin inhibits blood vessel growth and downregulates Akt phosphorylation and actin polymerization. Nutrition and Cancer 60(3): 412-420.

Shin, M., Kadowaki, T., Iwata, J.-i., Kawakubo, T., Yamaguchi, N., Takii, R., Tsukuba, T. \& Yamamoto, K. (2007).Association of cathepsin E with tumor growth arrest through angiogenesis inhibition and enhanced immune responses. Biological Chemistry, Vol. 388, 1173.

Siddiqui, M., Hafizoh, S., Ismail, Z., Sahib, H., Helal, M. H. S. \& Abdul Majid, A. M. S. (2009). Analysis of Total Proteins, Polysaccharides and Glycosaponins Contents of $<i>$ Orthosiphon stamineus </i>Benth. In Spray and Freeze Dried Methanol: Water(1:1) extract and its Contribution to Cytotoxic and Antiangiogenic Activities. Pharmacognosy Research 1(5): 320-326.

Sims, J. E., March, C. J., Cosman, D., Widmer, M. B., MacDonald, H. R., McMahan, C. J., Grubin, C. E., Wignall, J. M., Jackson, J. L. \& Call, S. M. (1988). cDNA expression cloning of the IL-1 receptor, a member of the immunoglobulin superfamily. Science 241(4865): 585-589.

Spitzweg, C. Scholz, I. V., Bergert, E. R., Tindall, D. J., Young C. Y. F., Goke, B. \& Morris, J. C. (2003). Retinoic acid-induced stimulation of sodium iodide symporter expression and cytotoxicity of radioiodine in prostate cancer cells. Endocrinology 144(8): 3423-3432.

Stoclet, J.-C., Chataigneau, T., Ndiaye, M., Oak, M.-H., El Bedoui, J., Chataigneau, M. \& Schini-Kerth, V. B. (2004). Vascular protection by dietary polyphenols. European Journal of Pharmacology 500(1): 299-313.

Suárez, Y. \& Sessa, W. C. (2009). MicroRNAs as novel regulators of angiogenesis. Circulation Research 104(4): 442-454.

Suganuma, M., Takahashi, A., Watanabe, T., lida, K., Matsuzaki, T., Yoshikawa, H. \& Fujiki, H. (2016). Biophysical approach to mechanisms of cancer prevention and treatment with green tea catechins. Molecules 21(11): 1566.

Tamura, M., Sebastian, S., Gurates, B., Yang, S., Fang, Z. \& Bulun, S. E. (2002). Vascular endothelial growth factor up-regulates cyclooxygenase-2 expression in human endothelial cells. The Journal of Clinical Endocrinology \& Metabolism 87(7): 3504-3507.

Therapontos, C., Erskine, L., Gardner, E. R., Figg, W. D. \& Vargesson, N. (2009) Thalidomide induces limb defects by preventing angiogenic outgrowth during early limb formation. Proceedings of the National Academy of Sciences USA 106(21): 8573-8578.

Tsuji, T., Sun, Y., Kishimoto, K., Olson, K. A., Liu, S., Hirukawa, S. \& Hu, G.-f. (2005). Angiogenin is translocated to the nucleus of HeLa cells and is involved in ribosomal RNA transcription and cell proliferation. Cancer research 65(4): 1352-1360.

Uhl, K., Cox, E., Rogan, R., Zeldis, J. B., Hixon, D., Furlong, L.-A., Singer, S., Holliman, T., Beyer, J. \& Woolever, W. (2006). Thalidomide Use in the US. Drug safety 29(4): 321-329.

Van Lint, P. \& Libert, C. (2007). Chemokine and cytokine processing by matrix metalloproteinases and its effect on leukocyte migration and inflammation. Journal of leukocyte biology 82(6): 1375-1381.

van Walsem, A., Pandhi, S., Nixon, R. M., Guyot, P., Karabis, A. \& Moore, R. A. (2015). Relative benefit-risk comparing diclofenac to other traditional non-steroidal anti-inflammatory drugs and cyclooxygenase-2 inhibitors in patients with osteoarthritis or rheumatoid arthritis: a network meta-analysis. Arthritis Research \& Therapy 17(1): 66.

Vargesson, N. (2009). Thalidomide-induced limb defects: resolving a 50-year-old puzzle. Bioessays 31(12): 1327-1336.

Varinska, L., Mirossay, L., Mojzisova, G. \& Mojzis, J. (2010). Antiangogenic effect of selected phytochemicals. Die Pharmazie-An International Journal of Pharmaceutical Sciences 65(1): 57-63.

Verma, R. P. \& Hansch, C. (2007). Matrix metalloproteinases (MMPs): chemical-biological functions and (Q) SARs. Bioorganic \& medicinal chemistry 15(6): 2223-2268.

Xu, B., Shen, F., Cao, J. \& Jia, L. (2013). Angiogenesis in liver metastasis of colo-rectal carcinoma. Front Biosci (Landmark Ed) 18: 1435-1443.

Yoysungnoen, P., Wirachwong, P., Changtam, C., Suksamrarn, A. \& Patumraj, S. (2008). Anti-cancer and anti-angiogenic effects of curcumin and tetrahydrocurcumin on implanted hepatocellular carcinoma in nude mice. World Journal of Gastroenterology :14(13): 2003-2009

Zhang, G., Miura, Y. \& Yagasaki, K. (2000). Suppression of adhesion and invasion of hepatoma cells in culture by tea compounds through antioxidative activity. Cancer Letters 159(2): 169-173

Zhang, J., Tang, Q., Xu, X. \& Li, N. (2013). Development and evaluation of a novel phytosome-loaded chitosan microsphere system for curcumin delivery. International Journal of Pharmaceutics 448(1): 168-174.

Zhu, Y., Bian, Z., Lu, P., Karas, R. H., Bao, L., Cox, D., Hodgin, J., Shaul, P. W., Thorén, P. \& Smithies, O. (2002). Abnormal vascular function and hypertension in mice deficient in estrogen receptor $\beta$. Science 295(5554): 505-508.
Submit your next manuscript to Journal of Angiotherapy published by EMAN Research

- Convenient online submission

- Thorough peer review

- No space constraints or color figure charges

- Immediate publication on acceptance

- Inclusion in Australian National Libraray and Google Scholar

- Both Open (80-100\% subsidized APC by ER) \& non-open access option

Submit your manuscript at

https://angiotherapy.emanresearch.org 